\title{
El $750^{\circ}$ Aniversario de la Carta Magna de 1215
}

Trescientos veinte años antes de la fundación de la ciudad de Lima, un rey inglés firmó un gran documento legal. Como los restos de Francisco Pizarro, ese documento, la Carta Magna de 1215, se conserva cuidadosamente como parte de la herencia nacional. Como Pizarro, su gloria había nacido de tiempos inquietos, cuando se consideraba generalmente que la espada era más poderosa que la pluma. Sin duda, si Pizarro contemplase hoy la gran ciudad de Lima, estaría muy sorprendido por sus límites y su desarrollo, y encontraría muy poco de su propia época. Es verdad. también que quienes fueron firmantes responsables de la Carta Magna estarían asombrados por las interpretaciones que sus sucesores han dado a su obra. El valor verdadero del trabajo de Pizarro y de los creadores de la Carta Magna está en la inspiración dada por aquellos que los siguieron para tomar lo que era mejor del concepto, su espíritu vital, y perfeccionar y adaptarlo para los usos de la humanidad. Como la espada angosta del Conquistador ha desaparecido ante anchas avenidas de la Lima moderna, del mismo modo el feudalismo estrecho de la Carta Magna se ha ensanchado hacia un espíritu general de libertad que ha dado vida a las palabras precisas de nuestra ley por los siglos de los siglos.

La Carta misma es un documento sencillo de sesentitrés cláusulas. No contiene nada:nuevo. Más bien es una promesa de conservar lo que ya había sido establecido. Su modelo es un documento, por el cual un rey más antiguo y más sabio, Enrique I, dió gratuitamente esas libertades a su pueblo en el año 1100. Los incidentes, también, de los que había nacido, se pueden comprender fácilmente. Un rey, poderoso y sabio, Enrique II habia creado un sistema de derecho, el que se extendió por todo el país trayendo los beneficios de la justicia real a muchos que no hubiesen disfrutado de tales derechos humanos de otra manera. Este rey era fuerte, además de ser justo, y aunque la exiensión del poder real quitó mucho del poder de los grandes caballeros, estos sufrieron sin quejarse. Su reinado fué seguido por el de un rey ausente, Ricardo I, Corazón de León, un gran guerrero, cuya dedicación a la causa cristiana lo llevó a las Cruzadas. Su descuido de su propio país, sin embargo condujo a los grandes caballeros, los Barones, a unirse otra vez en defensa de sus propios intereses y a resistir a mayores extensiones de la influencia del rey, que llevaba como consecuencia la pérdida de sus derechos privados.

Esta fué la situación heredada por el Rey Juan cuandó subió al trono en el año 1199, el trono no solamente de Inglaterra sinó, también, de esas partes de Francia del Norte que permanecieron bajo la dominación de 
los descendientes de los Normandos. Si hubiese sido hábil el Rey Juan, el país hubiera disfrutado de la misma consolidación de la influencia real y del gobierno central que existiera bajo el reinado de Enrique II. Es difícil traducir los pensamientos a través de más de siete siglos y medio para captar una imagen verdadera de la naturaleza del Rey Juan. Mucho de lo que sabemos de él, fué escrito por sus enemigos después de su muerte y no se puede considerar como imparcial. Podemos juzgar al hombre solamente por sus acciones. Quizás es digno de notarse que aunque hemos tenido ocho reyes llamados Enrique, ocho llamados Eduardo y seis llamados Jorge, nuestra Nación no ha repetido nunca el nombre del firmante desgraciado de la Carta Magna.

Los diecisiete años del reinado de Juan fueron muy agitados. En primer lugar, su mismo título al trono, no fué muy firme, porque se pensó que había victimado a su hermano mayor para ser rey. Sus relaciones con sus súbditos no fueron muy cordiales y las que sostuvo con los Barones llegaron a ser muy tirantes. Su oposición a nombrar Arzobispo de Cantorbery al excelente hombre Stephen Langton, condujo a que el país entero fuera puesto bajo entredicho papal. El país se enfrentó con una invasión extranjera para liberarlo de la tiranía creciente de un Rey que no tuvo ni poder para controlar a sus súbditos rebeldes, ni para unirlos contra la dominación amenazadora de ultramar. Fué obligado a someterse al Papa, cuya ayuda solicitó contra las fuerzas poderosas dirigidas por Stephen Langton, a la sazón, Arzobispo de Cantorbery, las cuales determinaron que el rey gobernaría según los preceptos establecidos por sus ilustres antepasados. Al fin, el 15 de junio de 1215 , en la pequeña isla de Runnymede, en medio del río Támesis, no muy lejos de Londres, se puso, de acuerdo con su pueblo, y firmó la Carta Magna, por la cual le garantizó las antiguas libertades y consintió en el nombramiento de un consejo de veinticinco poderosos Barones para asegurar el cumplimiento de su promesa.

Juan murió al año siguiente, pero tan importante se consideró la Carta Magna, que fué confirmada no menos de cinco veces hasta 1297. Durante los siglos siguientes, mucha de su significación literal fué perdida como este proceso de ficción acariciado por abogados ingleses, sus palabras fueron adaptadas a situaciones para las cuales, literalmente, no fueron nunca destinadas. Los grandes líderes de la Revolución Parlamentaria apelaron a su espíritu en vez de a sus palabras para justificar sus actividades. Vino a ser el símbolo de todo lo que se conoció por esa expresión flexible de "Common Law", la última hacia la cual en ausen-. cia de una Constitución escrita, el súbdito pudiese presentar una apelación. En esta época racional muchos han criticado la reverencia superticiósa con la que se ha considerado este documento sencillo durante los siglos y se han burlado de algunas de las interpretaciones dadas ambiciosamente a ciertas cláusulas. Todavía queda como una fuente de sorpresa, orgullo, e inspiración, no solamente para los ingleses, sino para todo el mundo que aprecia la libertad y mira hacia las Instituciones Británicas como hacia un ejemplo del Estado de Derecho, contra la regla de oscuridad y poder arbitrario. No es por casualidad que ese mismo día en que se festejaba el 750 aniversario de este gran acontecimiento en las Cortes Reales de Justicia con 
ceremonia espléndida, con la asistencia de todos los Jueces, que las cortes funcionaron como de costumbre para juzgar las causas de los súbditos antes de mediodía.

Por lo tanto, se cumplieron las palabras de la Carta:

"No venderemos a nadie, no negaremos a nadie, ni retardaremos a nadie, el derecho a la justicia".

H.H.A COOPER, M.A. LL.B. Catedrático Visitante de Derecho Constitucional en la Universidad Nacional Mayor de San Marcos. 